\title{
Migraine and premenstrual syndrome: comorbid disorders?
}

\author{
Eliana Meire Melhado (iD) Tulio Ruiz Eschiapati (D) Jessica Bidurin Picolo (iD Mariana Arantes Santos \\ Guilherme Martins Tahan (iD Rafael Dias Maria (iD Ana Clara Volpato de Matos
}

Medical School of Catanduva, Medicine, Catanduva, São Paulo, Brazil

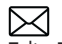

Tulio Ruiz Eschiapati

tulioeschiapati@hotmail.com

Edited by

Mario Fernando Prieto Peres

Marcelo Moraes Valença

\section{Keywords:}

Premenstrual syndrome

Headache

Neurology

Gynecology

Migraine

Smoking

Aura

\begin{abstract}
\section{Introduction}

Headache is a common symptom among women, including during the menstrual cycle. The migraine frequency in women who present migraine associated with the menstrual period ranges from $50 \%$ to $70 \%$. Premenstrual syndrome (PMS) is prevalent among women, affecting $80 \%$ to $90 \%$ of them throughout their lives.

\section{Objective}

The objectives of this study were to verify PMS prevalence and its characteristics among women who present with cephalalgia in the neurology ambulatory care unit and show the prevalence of headache and its association with PMS in the gynecology ambulatory care unit.

\section{Methods}

It is a descriptive and qualitative study which was carried out at Emilio Carlos Teaching Hospital in the neurology and gynecology ambulatory care units with women aged 18 to 52 years old. Eighty-seven questionnaires were distributed and self-applied throughout the year of 2018 for data collection. Each questionnaire consisted of 27 questions about the life cycle of the women and their headache episodes. The diagnostic criteria for headache and migraine from the International Headache Society were used. Criteria for PMS were met according to the quality of life questionnaire.

\section{Results}

In gynecology unit group, 9\% of the women did not present headache, 76\% had PMS and 94\% presented with headache during PMS. In neurology, 79\% of the women had PMS and $79 \%$ of the women who presented with cephalalgia also had PMS.

\section{Conclusion}

There is a large percentage of PMS in both groups, i.e. neurological unit and gynecological unit, showing it is not a spurious correlation.
\end{abstract}




\section{Introduction}

- eadache consists of any pain in the cephalic segment, which happens quite often, and it happens to women two or three times more often compared to men. ' Cephalalgia prevalence is similar among boys and girls and its incidence in girls increases after the menarche due to hormonal fluctuations. ${ }^{2,3}$ The migraine that happens during the menstrual period is known as menstrual migraine or headache and it can be considered to be a premenstrual migraine associated with the premenstrual syndrome (PMS) when it happens about a week before the menstrual period.

In women who present with migraine, clinical trials show that the frequency of the migraine episodes associated with their menstrual period ranges from $50 \%$ to $70 \%{ }^{4}$ One of the main causes of this association is the cyclic production of ovarian hormones which can affect the clinic expression of migraine according to scientific evidences that correlate the influence of these hormones with the nociceptive pathways (trigeminal ones), which change in periods such as pregnancy, menstruation and premenstrual period and menopause. $5,6,7$

The definition for migraine diagnosis related to menstruation is widely discussed and diverges about the preceding and consequent menstrual period between the authors. 8,9,10 The International Headache Society (IHS) considers a diagnosis if $90 \%$ of the crises happen between two days before the beginning of the period and until three days after it. ${ }^{11}$

PMS is prevalent among women, $80 \%$ to $90 \%$ of them can suffer from it throughout their lives. ${ }^{12}$ It is a cyclical disorder with several symptoms which start in the luteal phase and finish on the first days of the menstrual cycle. ${ }^{13}$

The association between women who suffer from menstrual migraine and premenstrual syndrome is probably high; however, it has not been clearly confirmed by clinical trials.

The aim of this study was to analyze the association between PMS and migraine, verifying the prevalence of PMS in women who present with cephalalgia in the neurology ambulatory care and showing the prevalence of cephalalgia and PMS in women in the gynecology ambulatory care at the same hospital.

It also intended to analyze if headache and PMS are comorbid disorders among those women.

\section{Methods}

The study was an observational cross-sectional study, which was carried out at Emilio Carlos Teaching Hospital (ECTH), in both neurology and gynecology ambulatory care units, with women aged 18 to 52 years old.
The research was submitted to the Ethics and Research Committee of Centro Universitário Padre Albino (UNIFIPA) connected to Plataforma Brasil (CAAE: 84943718.0.0000.5430).

Data were collected through 100 self-applied questionnaires which consisted of 27 questions related to the women's cyclical life and to the headaches and were distributed throughout the year of 2018. It was made clear to the women from the neurology and gynecology ambulatory care units the objectives and the purposes of the study, assuring them that they would be guaranteed anonymity and that the information would only be used for the research. After they had agreed, they signed the Informed Consent Form.

The diagnostic criteria for headache and migraine were the ones from the International Headache Society from 2018. ${ }^{14}$ The premenstrual syndrome criteria were met according to the 2003 Apolinario's study. ${ }^{14}$ There were 87 women enrolled in the study who: were aged 18-52 years old, took birth control pills, were or were not undergoing premenstrual syndrome or headache treatment and had or did not have comorbidities such as hypertension, diabetes mellitus (DM), asthma, controlled hypothyroidism and other clinically well-controlled conditions.

Inclusion criteria: women aged 18-52; taking birth control pills or not; undergoing premenstrual and/or headache treatment or not; no problems if presented with comorbidities such as hypertension, diabetes mellitus, asthma, controlled hypothyroidism and other clinically well-controlled conditions.

Exclusion criteria: diseases such as tuberculosis, HIV, cancer, lupus (or diseases similar to it); endocrine disorders which cause relevant hormonal alterations; uncontrolled cardiovascular or kidney disease; other autoimmune diseases or the ones associated with immunosuppression; use of chemotherapy drugs or hormones; pregnancy; and menopause.

After the questionnaires had been collected, data were inserted in an Excel spreadsheet and were analyzed by using the Fisher's exact test, odds ratio, the chi-square test and the t-test.

Fisher's exact and chi-square tests were used to verify whether women with PMS from gynecology unit had more headache and women with headache from neurology unit had more PMS.

Odds ratio was used to compare the occurrence of PMS in those who have migraine or the occurrence of migraine in those who have PMS in the whole group.

Chi-square and Fisher's exact tests were used to test whether women with PMS from gynecology unit have more menstrually related migraine (MRM) and women from neurology unit 
with MRM have more MRM. Fisher's exact test was used for association between smoking prevalence in women from Gynecology and Neurology units, for migraine with aura and smoking, for smoking and PMS, for association between types of migraine and use of contraceptives, and to compare the HIT scale with PMS.

Student t-test was used to compare the age of menarche with PMS and MRM.

Chi-square test was used to compare the number of PMS symptoms with MRM.

\section{Results}

Eighty-seven women were enrolled in the study, 42 women in the neurology ambulatory care unit presented with headache and 45 women complained about several gynecological problems in the gynecology ambulatory care unit. Only 4 out of $45(9 \%)$ women in gynecology unit did not present with headache. In neurology unit group, 33 out of $42(79 \%)$ women had PMS and 32 out of 34 women in gynecology (91\%) presented with headache (Figures 1 and 2). The average age of the women in the study was 31.29 years old and the median age was 30 years old. The average age of menarche was 12.32 years old and the median age was 12 years old. Among the women who presented with PMS and migraine: 13 gynecology patients present with menstrual migraine (MM) statistically significant comparing to non-MM $10(p<0.05)$; 22 neurology unit group patients present significantly with more MM comparing to the 6 women who do not have MM $(p<0.05)$. Women who have PMS also have more MM.

\section{Gynecology ambulatory care}

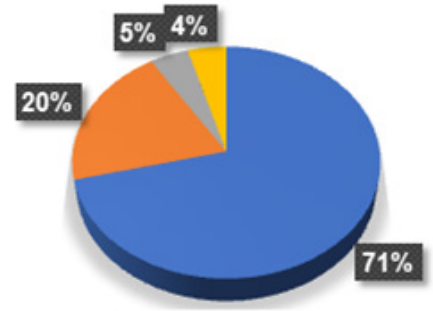

- Headache + PMS

Headache only

aMS only

none

Figure 1. Headache and premenstrual syndrome (PMS) in gynecology unit group

There is no significant difference in chances (odds ratio) of a woman who has PMS presenting with migraine or who has migraine presenting with PMS compared to the one who

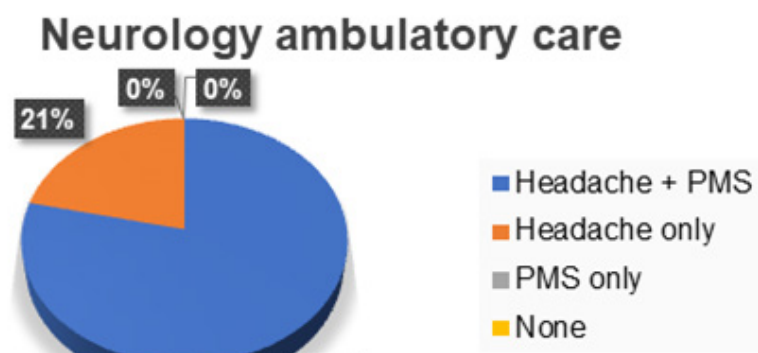

Figure 2. Headache and premenstrual syndrome (PMS) in the neurology unit group.

does not have PMS or migraine respectively in both groups $(p=0.225)$. However, the chance of a woman who has PMS having MM and a woman who presents with MM having PMS is 6.57 times greater $(95 \% \mathrm{Cl} 1.72-25.11)$ than not having MM and PMS, respectively $(p=0.005)$. There is a significant difference when comparing the occurrence of $M M$ in women who have PMS and the occurrence of PMS in women who have MM comparing to the ones who do not present with PMS and MM, respectively $(p=0.005)$.

Headache has significantly less impact on the gynecology group than on the neurology group ( $p=0.036)$ according to the Headache Impact test-6 (HIT-6) (Figure 3).

\section{Impact of Headache (HIT-6)}

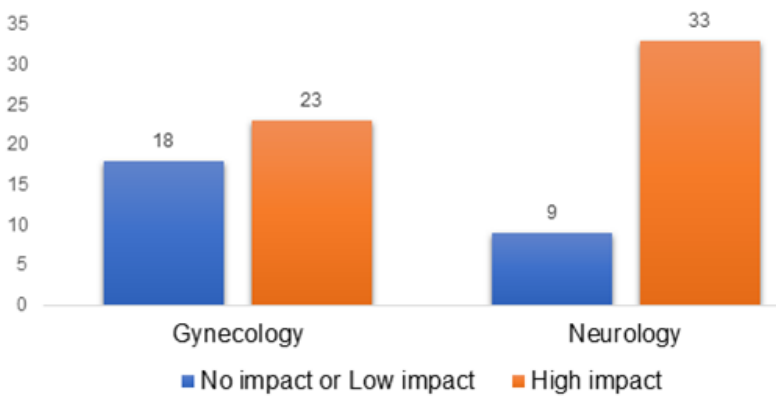

Figure 3. Impact of cephalalgia on gynecology and neurology unit groups.

HIT: Little or no impact $=$ HIT-6 score 49 or less. Some impact $=$ HIT6 score 50-55. Substantial impact $=$ HIT-6 score 56-59. Severe impact $=$ HIT -6 score $\geq 60$.

Figure shows little + no+ some in blue $=\mathrm{NO}$ or LOW IMPAC and substantial+severe in orange $=\mathrm{HIGH}$ IMPACT

The international classification of headache disorders according to IHS 2018 can be found in the following table (Table 1). There is a prevalence of migraine without aura in both groups. 
Table 1. Classification of headaches in the women in the study according to IHS 2018.

\begin{tabular}{|c|c|c|c|c|c|c|}
\hline Classification of Headaches & $\mathrm{n}$ & $\%$ & Neurology Unit (n) & $\%$ & Gynecology Unit (n) & $\%$ \\
\hline Migraine without aura & 46 & 55.0 & 29 & 69.0 & 17 & 41.0 \\
\hline Migraine with aura & 29 & 35.0 & 12 & 28.6 & 17 & 41.0 \\
\hline Probable migraine & 4 & 4.8 & & & 4 & 9.7 \\
\hline Tension-type headache & 4 & 4.8 & 1 & 2.4 & 3 & 7.3 \\
\hline Total & 83 & 100 & 42 & 100 & 41 & 100 \\
\hline
\end{tabular}

In addition, other variables were compared using statistical tests (Table 2).

Table 2. Results of other variables.

There are significantly more smokers in the gynecology group ( $p=0.016$ - Fisher's exact test).

The chance of a woman in the gynecology group being a smoker is 9.25 times higher $(95 \% \mathrm{Cl} 1.24$ to 84.88 ) than the chance of a woman in the neurology group being a smoker.

Smoking

There are not significantly more smokers in the group of women who have migraine with aura than in the group of women who have migraine without aura $(p=0.248)$.

There are not significantly more smokers in the group of women who have PMS than in the group of women who do not have PMS ( $\mathrm{p}=0.443$, Fisher's exact test).

Women in gynecology taking contraceptives do not present with significantly more migraine with aura than the ones who do not take contraceptives ( $p=0.700$ - Fisher's exact test).

Contraceptives $\quad$ Women in neurology group who take contraceptives do not present with significantly more migraine with aura than the ones who do not take contraceptives ( $p>0.99$ - Fisher's exact test).

Women in gynecology who take contraceptives do not present with significantly more migraine with aura than the women in neurology who take contraceptives ( $p>0.999$, Fisher's exact test).

There is no statistically significant difference in the ages of menarche of patients who have or do not have

Age of Menarche PMS $(p=0.253)$.

There is no statistically significant difference in the ages of menarche of patients who present and do not present with $M M(p=0.662)$.

\section{Discussion}

The present study is innovative because it shows the pathological association between PMS and migraine, mainly migraine in general (disregarding migraines associated with the menstrual cycle at a first moment).

Studies analyzed the relation between MM and mood disorders, such as PMS, premenstrual dysphoric disorder (PMDD) and major depression, trying to determine an in common pathogenic mechanism. The comorbidity may be related to the ovary hormone fluctuations: those disorders are more frequent during periods of estrogen deprivation (such as in postpartum period and PMS). Furthermore, the prodromal phase of migraine is associated with dopaminergic symptoms and the mood disorders are characterized by the dopamine imbalance. ${ }^{15}$

In our study, PMS did not make MM worse, different from previous studies which show menstrual headache as inca pacitating, limiting daily activities. ${ }^{16}$

A study showed that the number of prodromal symptoms in the group of women who presented with MM was larger than in the non-MM group. Researchers classified the episodes of PMS migraine into the premenstrual period (-2 and -1 days) (46 patients), menstrual period (from day 1 to day 3) $(90$ patients) and late menstrual period (day 4 to day 7 ) (19 patients). The duration of more intense headache and several symptoms frequently associated with it were observed and it was suggested that it could reflect an increase in excitability and/or susceptibility in these patients' brains. ${ }^{17}$

However, despite more prodromal symptoms, Merle and Diamond demonstrated that the clinical characteristics of $M M$ are similar to non-MM. ${ }^{18}$

About the research on comorbidity, when the menstrual migraine fraction was separated, it was observed that there is neither comorbidity nor risk factor for PMS. Nonetheless, PMS is a risk factor for and comorbid for MM which makes 
it a unilateral comorbidity.

The flaw in this study is the small sample size which has not allowed an assessment of the menstrual migraine duration. It confirms Fettes's work ${ }^{19}$ which states that the cause of menstrual migraine is different from PMS. A migraine episode that happens between 7 and 2 days before the menstrual cycle is considered premenstrual and associated with PMS, which does not correspond to MacGregor's definition of migraine that states it happens between 2 and 3 days before the menstrual cycle..$^{19}$ However, it contradicts others who claim the existence of an association without stating it categorically that there is comorbidity and also that some neuroendocrinological findings are shared by both problems (MM and PMS). ${ }^{20}$

There is no MM interference in PMS symptom in our study and there were no data for comparison.

Women who have migraine with aura smoke as much as the ones who have migraine without aura. Migraine with aura is a serious risk factor for stroke in young women and it shows that these patients do not know about it, which indicates problems in the anti-smoking campaigns of health programs. These agencies should advise this group to stop smoking, practice exercises and attend support groups.

The study also showed that PMS is not related to smoking. It was believed that stress could lead to female smoking, but there are not scientific data about it.

To sum up, the strengths of this study were the following: patients in two different areas (neurology and gynecology) and the questionnaire that identified details about the menstrual cycle and possible comorbidities. The flaws were the small sample size, because it was difficult to keep women focused on answering the questionnaire until the end, and also because the PMS diagnosis was based on a questionnaire from a textbook and not on the DSM-5.

Despite the limitations, it was possible to identify interesting results to improve future researches on this subject whose objective is general women's health, which must be treated with dignity in order to have a better quality of life through government actions and health care.

\section{Conclusions}

The prevalence of migraine in gynecology unit and PMS in neurology unit is high and the relation between PMS and migraine is significant in both groups. Migraine and PMS are, therefore, bilaterally associated disorders. In spite of that,
PMS indicates a risk for MM, but MM does not indicate a risk for PMS, which is not comorbid in this way.

In clinical practice, it is observed that women look for a neurologist because migraine is more incapacitating than PMS. Thus, it can be concluded that it is really necessary to advise gynecologists to refer their patients to have access to specialized treatment for cephalalgia and neurologists need to refer their patients to gynecologists occasionally to treat PMS symptoms.

\section{Financing: No \\ Conflict of interests: No}

Author Contributions: Author Contributions: EMM and TRE - Statistical Analysis, Writing, Reviewing and Editing; JBP - Data Collection and Writing; MAS, GMT, RDM and ACVM - Conceptualization and Writing

Eliana Meire Melhado

https://orcid.org/0000-0003-3699-1064

Túlio Ruiz Eschiapati

https://orcid.org/0000-0002-1762-9097

Jéssica Bidurin Pícolo

https://orcid.org/0000-0003-1901-8254

Mariana Arantes Santos

https://orcid.org/0000-0001-8107-7250

Guilherme Martins Tahan

https://orcid.org/0000-0001-8920-8665

Rafael Dias Maria

https://orcid.org/0000-0002-5251-9678

Ana Clara Volpato De Matos

https://orcid.org/0000-0002-4723-3499

\section{References}

1. Buse DC, Loder EW, Gorman JA, Stewart WF, Reed ML, Fanning KM, . . . Lipton RB. Sex Differences in the Prevalence, Symptoms, and Associated Features of Migraine, Probable Migraine and Other Severe H eadache: Results of the A merican Migraine Prevalence and Prevention (AMPP) Study. Headache: The Journal of Head and Face Pain 2013;53(1):1 278-1299 Doi: $10.1111 /$ head. 12150

2. Pavlović JM, Allshouse AA, Santoro NF, Crawford SL, Thurston RC, Neal-Perry GS, .. . Derby CA. Sex hormones in women with and without migraine: evidence of migraine-specific hormone profiles. Neurology 2016;87(2):49-56 Doi: 10.1212/ WNL.0000000000002798

3. Martin VT, Pavlovic J, Fanning KM, Buse DC, Reed ML and Lipton RB. Perimenopause and menopause are associated with high frequency headache in women with migraine: results of the American migraine prevalence and prevention study. Head- 
ache: The Journal of Head and Face Pain 2016;56(3):292-305 Doi: 10.1111/head. 12763

4. Cupini L, Matteis M, Troisi E, Calabresi P, Bernardi G and Silvestrini $M$. Sex-hormone-related events in migrainous females. A clinical comparative study between migraine with aura and migraine without aura. Cephalalgia 1995; 15(4): 140-144 Doi: 10.1046/j. 1468-2982.1995.015002140.x

5. Loder E, Rizzoli P and Golub J. Hormonal Management of Migraine Associated With Menses and the Menopause: A Clinical Review: CME. Headache: The Journal of Head and Face Pain 2007;47(5):329-340 Doi: 10.1 11 1/j. 1526-4610.2006.00710.x

6. Puri V, Puri S, Svojanovsky S, Mathur S, Macgregor R, Klein R, . . Berman $N$. Effects of oestrogen on trigeminal ganglia in culture: implications for hormonal effects on migraine. Cephalalgia 2006;26(6):33-42 Doi: / 10. 111 1/i.1468-2982.2005.00987.x

7. Calhoun AH. Migraine and menopause. $2004 ; 7)$ : Doi: 10.1111/i.1526-4610.2004.04020.x

8. Miziara L, Bigal ME, Bordini CA and Speciali JG. Cefaléia menstrual: estudo semiológico de 100 casos. Arquivos de Neuro-Psiquiatria 2003;61(8):596-600 Doi: 10.1590/S0004282X2003000400013

9. Szekely B, Botwin D, Eidelman BH, Becker $M$, Elman $N$ and Schemm R. Nonpharmacological treatment of menstrual headache: relaxation-biofeedback behavior therapy and person-centered insight therapy. Headache: The Journal of Head and Face Pain 1986;26(9):86-92 Doi: 10.1111/j.15264610.1986.hed2602086.x

10. De Lignieres $B$, Vincens $M$, Mauvais-Jarvis $P$, Mas J, Touboul $P$ and Bousser M. Prevention of menstrual migraine by percutaneous oestradiol. British medical journal (Clinical research ed.) 1986;293(10): 1540 Doi: 10.1136/bmj.293.6561.1540

11. Arnold M. Headache classification committee of the international headache society (IHS) the international classification of headache disorders. Cephalalgia 2018;38(11):1-211 Doi: 10.1177/0333102417738202
12. Reid RL and Soares CN. Premenstrual dysphoric disorder: contemporary diagnosis and management. Journal of obstetrics and gynaecology Canada 2018;40(12):215-223 Doi: 10.1016/i.jogc.2017.05.018

13. Warnock JK, Cohen LJ, Blumenthal H and Hammond JE. Hormone-Related Migraine Headaches and Mood Disorders: Treatment with Estrogen Stabilization. Pharmacotherapy: The Journal of Human Pharmacology and Drug Therapy 2017;37(13): 120 128 Doi: 10.1002/phar. 1876

14. Appolinário J. TDPM: transtorno disfórico pré-menstrual. São Paulo. Editora Segmento 2003; 14).

15. Negro A, Napoletano F, Lionetto L, Marsibilio F, Sani G, Girardi $P$ and Martelletti P. Treatment of menstrual migraine: utility of control of related mood disturbances. $E_{X}$ pert review of neurotherapeutics 2014;14(15):493-502 Doi: 10.1586/14737175.2014.906304

16. Ribeiro HJM. Influência hormonal na enxaqueca. 2012;16):

17. Güven B, Güven H and Çomoğlu S. Clinical characteristics of menstrually related and non-menstrual migraine. Acta Neurologica Belgica 2017; 1 17(17):671-676 Doi: 10.1007/ s13760-017-0802-y

18. Diamond ML, Cady RK, Mao L, Biondi DM, Finlayson G, Greenberg SJ and Wright $P$. Characteristics of migraine attacks and responses to almotriptan treatment: a comparison of menstrually related and nonmenstrually related migraines. Headache: The Journal of Head and Face Pain 2008;48(18):248-258 Doi: 10.1111/j.1526-4610.2007.01019.x

19. Fettes I. Menstrual migraine: methods of prevention and control. Postgraduate medicine 1997;101(19):67-77 Doi: 10.3810/ pgm. 1997.05.236

20. Facchinetti F, Sances G, Borella P, Genazzani AR and Nappi G. Magnesium prophylaxis of menstrual migraine: effects on intracellular magnesium. Headache: The Journal of Head and Face Pain 1991;31(20):298-301 Doi: 10.1111/j.15264610.1991.hed3105298.x 